Published in final edited form as:

J Nutr Educ Behav. 2014 January ; 46(1): 26-33. doi:10.1016/j.jneb.2013.06.001.

\title{
Examining the influence of price and accessibility on willingness to shop at farmers' markets among low-income eastern North Carolina women
}

\author{
Jared T. McGuirt, MPH [Research Assistant] \\ University of North Carolina at Chapel Hill, Department of Nutrition 2200 McGavran-Greenberg \\ Hall, Chapel Hill NC 27599 Telephone: (910) 249-2296
}

Stephanie B. Jilcott Pitts, PhD [Assistant Professor]

East Carolina University, Department of Public Health 600 Moye Blvd, MS 660 Greenville, 27834

Telephone: (252) 744-4034; Fax: (252) 744-4008

\section{Rachel Ward, MPH [Research Assistant]}

East Tennessee State University, Department of Community Health Johnson City, TN Telephone: 828-808-7913

\section{Thomas W. Crawford, PhD [Associate Professor]}

Department of Geography A-238 Brewster Bldg. East Carolina University Greenville, NC 27858

Phone: (252) 328-6082; Fax: (252) 328-6054

\section{Thomas C. Keyserling, MD, MPH [Associate Professor]}

Division of General Medicine and Clinical Epidemiology Department of Medicine School of Medicine University of North Carolina at Chapel Hill Telephone: 919-966-2276; Fax:

919-966-2274

\section{Alice S. Ammerman, DrPH, RD [Professor] \\ Gillings School of Global Public Health \& School of Medicine University of North Carolina at Chapel Hill, Department of Nutrition, CB\#7461 Chapel Hill, NC 27599 Telephone: (919) 966-6082}

\section{Abstract}

Objective: To examine the influence of farmers' market pricing and accessibility on willingness to shop at farmers' markets, among low-income women.

Design: Qualitative interviews using scenarios with quantitative assessment of willingness to shop at farmers' market given certain pricing and accessibility scenarios.

Setting: Eastern North Carolina.

\footnotetext{
(C) 2013 Society for Nutrition Education. Published by Elsevier Inc. All rights reserved mcguirtj@live.unc.edujilcotts@ecu.eduwardrk@goldmail.etsu.educrawfordt@ecu.edujato@med.unc.edualice_ammerman@unc.edu. Publisher's Disclaimer: This is a PDF file of an unedited manuscript that has been accepted for publication. As a service to our customers we are providing this early version of the manuscript. The manuscript will undergo copyediting, typesetting, and review of the resulting proof before it is published in its final citable form. Please note that during the production process errors may be discovered which could affect the content, and all legal disclaimers that apply to the journal pertain.
} 
Participants: Thirty seven low-income women of child-bearing age (18-44 years) receiving family planning services at the health department.

Phenomenon of Interest: Willingness to shop at a farmers' market.

Analysis: Fisher's exact test was used to examine associations between willingness to shop at farmers' markets by urban/rural residence, race, and employment status. Direct quotations relevant to participants' use of farmers' markets were extracted based upon a positive deviance framework.

Results: Participants were increasingly willing to shop at the farmers' market when price savings increased and when the market was incrementally closer to their residence. Willingness was highest when there was at least a $20 \%$ price savings. Participants seemed to be influenced more by a visual representation of a greater quantity of produce received with the price savings rather than the quantitative representation of the money saved by the reduced price.

Conclusions and Implications: Future farmers' market interventions should take into account these consumer level preferences.

\section{Keywords}

farmers' markets; price savings; fruit and vegetable consumption; North Carolina

\section{INTRODUCTION}

Despite the health benefits associated with produce consumption, ${ }^{1}$ most U.S. residents fall short of recommended consumption levels, with only $26 \%$ of US adults meeting vegetable recommendations and only $34 \%$ of US adults meeting fruit recommendations as of 2009. 2,3 Those who are low-income commonly cite high prices and lack of accessibility as barriers to produce consumption. ${ }^{4-7}$ This lack of accessibility is concerning, as residential proximity to food venues with a wide variety of produce (e.g., supermarkets and farmers' markets) has been associated with lower body mass index (BMI) ${ }^{8,9}$ as well as fruit and vegetable consumption among lower income consumers. ${ }^{10}$ Taken together, research suggests that when fruits and vegetables are less costly and more accessible, individuals are more likely to purchase and consume them. ${ }^{11-14}$

Farmer-to-consumer direct marketing of produce via farmers' markets, produce stands, or pick-your-own farms, is posited as an important strategy to promote produce consumption among low-income consumers who live in areas with low produce accessibility. ${ }^{15}, 16$ These suggested strategies are driven by the expectation that farmers' market produce may cost less than produce found at traditional food venues. For example, a California study ${ }^{17}$ found a 34\% overall price savings between produce purchased at farmers' markets versus the average price of produce at proximal supermarkets. A North Carolina study ${ }^{18}$ found an $18 \%$ overall price savings between produce at farmers' markets versus nearby supermarkets. Finally, consumers given vouchers for produce at a farmers' market bought more fruits and vegetables than consumers given vouchers for produce at a supermarket, ${ }^{19}$ suggesting that consumers may prefer produce purchased at farmers' markets versus produce from supermarkets. 
However, there is little published literature to document the direct relationship between shopping at farmers markets and increased fruit and vegetable consumption, though some evidence for effectiveness exists. A study by Kaiser Permanente ${ }^{20}$ demonstrated increased fruit and vegetable consumption in patrons of worksite farmers' markets. Two Special Supplemental Nutrition Program for Women, Infants, and Children (WIC) Farmers' Market Nutrition Program (FMNP) related studies have demonstrated increased fruit and vegetable consumption with participants given farmers' market coupons. ${ }^{19,21}$ Evans et al $2012^{22}$ found that introduction of farmers' markets in low-income areas increased fruit and vegetable consumption among community residents.

Low-income consumers tend to shop at farmers markets less frequently than their higher income counterparts, citing higher perceived price and limited access as barriers. ${ }^{23}$ In terms of consumer proximity to farmers' markets, 1 study reported a range of 6 to 17 miles distance from consumers' homes to the farmers' market ${ }^{24}$ and another study reported that customers traveled 17 to 18 minutes to reach the farmers' market. ${ }^{25,}{ }^{26}$ Little research has been conducted from a public health perspective to examine price savings or accessibility thresholds that are needed to motivate low-income consumers to patronize farmers' markets. This information is necessary as new federal public health initiatives are promoting direct marketing opportunities like farmers' market in an effort to increase access, availability, and consumption of fruits and vegetables. Therefore, the joint association of potential farmers' market price savings and increased accessibility of farmers' markets on willingness to shop at farmers' markets was examined among low-income women in eastern North Carolina.

\section{METHODS}

\section{Theoretical Background}

A method similar to an econometric technique known as "contingent valuation" was used for the purpose of understanding consumers" "stated preference" for shopping at the farmers' market given particular price and accessibility conditions. ${ }^{27}$

\section{Study Participants}

This study was ancillary to the Integrated Screening and Health Assessment, Prevention and Evaluation (InShape) Study to examine cardiovascular disease risk factor prevalence among low-income women of child-bearing age (18-44 years) receiving family planning services at the Pitt County Health Department Title X family planning clinic. Pitt County (population $171,134)^{29}$ is located in North Carolina, with Greenville (pop. 84,554) ${ }^{30}$ as its major city. Upon InShape enrollment, women were asked to participate further in a qualitative study investigating food shopping patterns. Participants were selected based on indicating interest on the InShape Study screening questionnaire. Attempts were made by the study staff to have equal representation of race, employment status, and rural/urban residence. Upon agreeing to participate, a meeting time and location were established to conduct the study interview. During the meeting, participants were informed of all aspects of the study and were offered a chance to ask questions. This study was approved by the university institutional review board and all participants provided written informed consent. 


\section{In-depth Interviews}

In-depth, qualitative interview scripts were developed through expert consensus of the research team, with revisions made after pilot testing. Interviews were conducted by 2 trained interviewers (JM and SJP) with 37 women enrolled in the InShape Study. Interviews lasted between 45-60 minutes, and participants were compensated $\$ 20$ for their time. Questions assessed their food purchasing activity space to capture geographic patterns of their normal food shopping patterns and their use of food venues such as supermarkets, restaurants, and farmers' markets. As a part of the interview, participants were asked to complete a "contingent valuation" exercise wherein they were given a visual representation of different price and accessibility scenarios measuring their willingness to shop at a farmers' market when compared to a supermarket. The visual price and accessibility scenarios assessed the price for the same market basket of produce at a farmers' market versus a supermarket, and an indicator of access or time required driving to a farmers' market versus supermarket. In-depth interviews were audio recorded and transcribed verbatim for analysis by the same research staff that conducted the interviews (JM).

\section{Price scenarios}

To examine how price savings may facilitate farmers' market use, the farmers' market was assumed to confer a price savings, which is consistent with the majority of previous research, ${ }^{17,18,31}$ including a research study in the same area where the interviews were conducted which found a price savings at farmers markets compared to supermarkets. ${ }^{18}$ Percentage price savings $(5,10,20,30$, and 40 percent) were presented visually as discounts from a standard amount of $\$ 8$, a realistic amount to be provided at the beginning of the market season by the Special Supplemental Nutrition Program for Women, Infants, and Children (WIC) Farmers' Market Nutrition Program.

Scenarios were presented to examine how 2 different "stimuli" (discounted price ("price") and increased produce quantity ("amount")) might influence participant's willingness to shop at farmers' markets. The first stimulus "price" was the actual price (dollar amount) that the consumer would pay at the farmers' market versus the supermarket for the same market basket of produce, given particular percent discounts at the farmers' market. For example, the $20 \%$ discount visually displayed the market basket priced at $\$ 6.40$ at the farmers' market versus $\$ 8$ at the supermarket.

The second stimulus "amount" was a picture of the amount of produce a consumer could procure at the farmers' market compared to the supermarket given the particular percent discount at the farmers' market. For example, a 20\% discount from the standard amount of $\$ 8$ at the farmers' market compared the supermarket would yield 15 vegetables (e.g., 10 squash and 5 bell peppers) at the farmers' market compared to 8 vegetables (e.g., 5 squash and 3 bell peppers) at the supermarket.

To determine prices of produce quantities, a member of the research team went to a local supermarket to establish the price per pound of various produce. The researcher then calculated the amount of produce that would fit under each hypothetical percent discounted amount at the farmers' market, given the per pound price of the produce at the supermarket.

J Nutr Educ Behav. Author manuscript; available in PMC 2015 January 01. 
A picture representation of the standard $\$ 8$ amount was created, as well as a comparative picture for the amount of produce in each percentage discount category. The pictures representing produce at the standard and discounted prices were presented side-by-side for comparison. This second depiction was designed to learn about consumers who were motivated by greater quantity for a given price. To avoid bias due to vegetable preferences, participants were told not to focus on the type of vegetable but on the price and quantity, and were told to assume it was a market basket of their favorite produce.

\section{Accessibility scenarios}

To examine how accessibility may facilitate farmers' market use, the first 6 participants were given a condition where the farmers' market was assumed to be 5, 10, and 15 minutes further from the participants' residential address than the supermarket. The researchers then added a new condition to the interview guide, where the farmers' market was assumed to be 5,10 , and 15 minutes closer to the participants' residential address than the supermarket. Therefore, the first 6 recipients only received the "further" condition, and there were 31 participants who received both the "further" and "closer" conditions.

The price and accessibility scenarios were combined, so that there were a total of 4different scenarios, outlined in Figure 1. In Scenario 1, women were told that the farmers' market was 5 minutes closer to their residential address than the supermarket, and they would receive a $5 \%$ discount on produce, shown by the actual price. The time factor incrementally changed to the farmers' market being 10 and 15 minutes closer than the supermarket, and the price discount factor changed to $10,20,30$, and $40 \%$ discounts to represent price savings at the farmers' market versus supermarket for the same market basket of produce. Scenario 2 was similar to Scenario 1 except that women were told that the farmers' market was 5, 10, or 15 minutes further from their residential address than the supermarket.

In Scenario 3, women were told that the farmers' market was 5, 10, or 15 minutes closer to their residential address than the supermarket but the incremental price discounts were represented visually as the amounts of produce they could purchase for the discounted price. Scenario 4 was similar to Scenario 3 except that women were told that the farmers' market was 5,10 , or 15 minutes further than the supermarket.

The 6initially interviewed participants were shown only Scenarios 1 and 2 and thus were presented with 30 hypothetical purchase situations. Combining the various price and time factors or the 4scenarios yielded a total of 60 hypothetical purchase situations for the next 31 participants who were interviewed.

\section{Analysis}

Quantitative analysis—Each participant was assigned a "willingness to shop" score based on number of times she said "yes" to each purchasing situation. Frequencies and percentages of women willing to shop at a farmers' market for each price/accessibility situation were generated. Differences were examined between willingness to shop at farmers' markets by urban/rural residence, prior farmers' market shopping behavior, race, and employment status by comparing frequencies between strata. This stratification was 
done to see if different marketing strategies are needed to reach specific populations.

Location of residence was assessed by mapping resident addresses and municipal boundaries using ArcGIS software (ArcMap version 10.0, ESRI Inc., Redlands, CA, USA, 2010). Urban was defined as living within a city municipal boundary, and Rural was defined as living outside of city municipal boundary. Given the small sample size, Fisher's exact test was used to examine associations between variables. All statistical analyses were conducted using R statistical software (R version 2.14.1, R Foundation for statistical Computing Vienna, Austria, 2011).

Qualitative analysis-After all in-depth interviews were transcribed verbatim, direct quotations relevant to participants' use of farmers' markets were extracted directly from the transcripts by the research team. Using the "willingness to shop" score, we selected 3 "positive deviants", or women who would shop at a farmers' market in every scenario, and 2 "negative deviants", or women who would never shop at a farmers' market. ${ }^{32}$ Differences between positive and negative deviants were extracted and quotes were extracted from the interviews to provide clarity.

\section{RESULTS}

The mean age of participants was 27.6 years (range: 18-41 years). The majority reported African American race (59\%), with the rest reporting Caucasian race (41\%). The population was almost evenly split between urban (54\%) and rural (46\%) residence, employment status (Employed: 49\%; Not employed: 51\%), and Supplemental Nutrition Assistance Program (SNAP) use (Yes: $51 \%$; No: 49\%).

The majority of participants (except for 2 negative deviants, discussed below) indicated they would shop at a farmers' market in at least 1 scenario, and 3 participants indicated they would shop at a farmers' market in every scenario (positive deviants, also discussed below). There were 16 scenarios in which all participants were willing to shop at the farmers' market, all of which were when the farmers' market was closer to the residential address when compared to the supermarket. The scenarios where women were least willing to shop at a farmers' market were the scenarios in which the farmers' market offered a 5\% discount but was 15 minutes further from the residential address.

Frequencies and percentages of women willing to shop at farmers' markets in each of the 4 scenarios are in Figure 2. Participants were increasingly willing to shop at the farmers' market when the farmers' market was incrementally closer (Figures 2a and 2c), and were decreasingly willing when the farmers' market was incrementally further (Figures $2 b$ and $2 d)$.

Increasing levels of price savings increased the percentage of women willing to shop at the farmers' market compared to the supermarket. Increasing price savings appeared to attenuate the effect of increased distance (decreased accessibility) on willingness to shop at the farmers' market.

Overall, most consumers were motivated to shop at a farmers' market by the visual depiction of greater amount of produce purchased at a discount (the "amount stimulus", or a 
visual depiction of more produce for the same amount of money) compared to discounted price (the "price" stimulus, or less money for the same amount of produce).

The largest increase in willingness to shop at the farmers' market appeared at the $20 \%$ price savings level, particularly when there was less access (greater distance) to the farmers' market compared to the supermarket. This was consistent for both the price and amount stimuli. A statistically significant increase in willingness to shop at the market was found between the $10 \%$ and $20 \%$ discount when there was a $5(\mathrm{p}=.02)$ or 10 minute greater distance ( $\mathrm{p}=.02)$ to the farmers' market in the price stimulus, and when there was a 15 minute greater distance to the farmers' market in the amount stimulus $(\mathrm{p}=0.02)$. For both the amount stimulus and the price stimulus, the sharpest decrease in willingness to shop at the farmers' market occurred when the farmers' market went from 10 minutes to 15 minutes further from the residential address (Figures $2 \mathrm{~b}$ and $2 \mathrm{~d}$ ).

In the scenarios where the farmers' market was closer to the residential address, rural residents appeared slightly more willing than urban residents to shop at a farmers' market when it was closer, although the differences were not statistically significant. For example, in the scenarios where the farmers' market was 10 minutes closer, all rural residents indicated they would shop at the farmer's market at every level of price savings. By contrast, urban residents reported mixed interest in shopping at the farmers' market for all price and distance scenarios, whereby $100 \%$ willingness to shop at the farmers' market at any distance was only reached when the price savings reached $40 \%$.

In nearly every scenario, participants who currently shopped at a farmers' market were more willing to shop at a farmers' market compared to those who do not currently shop at a farmers' market. Of the participants who answered yes on less than $75 \%$ of scenarios, $86 \%$ (12 out of 14) did not currently shop at a farmers' market. Of those who answered yes on more than $75 \%$ of scenarios, $43 \%$ did not currently shop at the farmers' market. The only exception to this was in the produce quantity stimulus, where both groups were nearly unanimous in their willingness to shop if the farmers' market was closer to their residential address than the supermarket.

There were no clear racial differences in willingness to shop at a farmers' market, and there were no statistically significant differences between willingness to shop at a farmers' market based upon employment status.

Qualitative feedback about farmers' markets was examined, comparing those willing to use the farmers' market in every scenario $(n=3)$, or "positive deviants", and those who would never shop at the farmers' market $(\mathrm{n}=2)$, or "negative deviants". All of the positive deviants were African American, mean age of 31 years, and 2 of 3 did not currently shop at a farmers' market. The positive deviants mentioned price savings and the need to feed many people with constrained resources as reasons why they would shop at a farmers' market when it was both more and less accessible:

"Well I would like to try [the] farmers' market if the produce is cheaper ...I would definitely like to try it."-Positive Deviant 1 (Non-Farmer's Market Shopper) 
"Quality and price, ... it's worth it in the long run to just go ahead and go to the place you really want to go and get what you want, instead of going to the supermarket and not being satisfied, then having to go again, so now you've driven 2 times, that's a waste.". - Positive Deviant 2 (Farmers' Market Shopper)

"I definitely would go. I still would go 'cause we have a lot of people to feed, so it's worth it to me to spend the extra dollar in gas and feed 3 more people."-

Positive Deviant 2 (Farmers' Market Shopper)

The positive deviant that did not currently shop at the farmers' market reported personal access to a garden and unfamiliarity with farmers' markets as reasons for their current nonshopping status:

"I just have never been introduced to it...probably if somebody were you know take me out there, or you know introduce me to it than I probably would go. Tell me how good the food is there, the vegetables and the produce...yeah. Because I do buy vegetables, so...."

"No I just don't [shop at the farmers' market]. Well my grandma and my granddaddy got a garden so we go in there and get stuff out of the garden."

The negative deviants were an average age of 23.5 years, 1 black and 1 white, 1 in school and 1 not in school, and neither shopped at a farmers' market. Both of the negative deviants were interviewed with the initial and not the revised qualitative interview guide, which only included questions about the farmers' market being further than the supermarket. Despite this, participant responses seemed to indicate that they would not use a farmers' market regardless of greater accessibility (closer distance to residential address). Neither of the negative deviants suggested elevated price or distance as being a reason for them not shopping at a farmers' market. Participants cited lack of trust in farmers' market produce and lack of convenience as reasons they would never shop at a farmers' market:

"I really don't trust the farmers' market.... Money don't make the world go round with me. I'd rather pay the extra to know where it comes from..."

As well as convenience and it being outside of usual routine:

"I mean it's my routine [shopping at supermarkets]. I guess because I am usually so busy, that convenience and things like that is like my most, really why I shop where I shop... if I had more time I would eventually visit the farmers' market, but right now I gotta be in and out".

\section{DISCUSSION}

Results suggest price was the most important factor increasing willingness to shop at a farmers' market among our sample of low-income women. Greater produce price savings appeared to ameliorate the negative effect of increased distance (lower accessibility) on willingness to shop at the market. This result is consistent with other studies suggesting price is a prominent factor in consumer decision-making relative to fruit and vegetable purchase and consumption. ${ }^{7}$ In fact, Glanz and colleagues ${ }^{28}$ reported that fruit and vegetable cost was most important to young low-income women. Price was also an important factor in

J Nutr Educ Behav. Author manuscript; available in PMC 2015 January 01. 
low and moderate-income consumers' willingness to shop at farmers' markets in previous studies. ${ }^{34,35}$

Why an image may influence willingness to purchase perceived value differently than text or a numeric representation, especially for food items like fruits and vegetables, is unclear. In general, there is limited evidence in the literature for how the effects of food sale promotions are mediated by different promotional approaches. ${ }^{36}$ No studies were found that compared a visual depiction of purchasing power versus nominal value. From a cognitive perspective, the visual depiction may assist comprehension of value through improved mental modeling, helping to better match perceived value to existing knowledge of value. ${ }^{37}$

The principles of behavioral economics may also explain the findings of this paper. External cues like packaging and presentation can alter food decisions, a tactic used by food manufacturers and marketers to increase consumption of their foods. ${ }^{38}$ Studies have demonstrated increased likelihood of purchase when there is a perception of greater value. ${ }^{39}$ A picture of greater perceived purchasing power (amount of produce) may help the consumer (especially low-income consumers) understand the benefits they will receive for exchanging financial resources for that particular good (in this case, produce). ${ }^{40,41}$ This may encourage utilitarian attributes associated with goals of "getting more for the money" and eating healthier. ${ }^{42}$

These results also indicate that the price point for produce is important, as the largest increase in consumer willingness to shop at the farmers' market appeared at the $20 \%$ price savings level. Previous studies suggest that produce at farmers' markets approaches this price point compared to supermarkets prices, ${ }^{17,} 18$ thus current price points are within customer preferences Marketing strategies for farmers' markets should consider this price point.

In the current study, while price (represented by amount of produce shown) was the most important factor in women's willingness to shop at farmers' markets, distance to the farmers' market also proved influential. Results suggest maximum potential market usage likely occurs when markets are within a 15 minute driving distance from low-income areas. Baker et al found that Vermont farmers' market customers traveled 17-18 minutes to the market ${ }^{25}$ and a review of the literature reported that farmers' market customers traveled an average of 6-17 miles to the market. ${ }^{24}$ These studies were among higher income consumers who may have more time to shop and greater transportation resources than the population in the current study. Cultural differences may also explain the slight differences in findings between the current study and the previous studies, as the current study included a predominantly African American sample.

Not surprisingly, women who previously shopped at farmers' markets indicated greater willingness to shop at the farmers' market in each scenario compared those who did not currently shop at the farmers' market. These results suggest comfort with shopping in this environment may play a role in willingness to shop at farmers' markets. This finding is similar to that found in a study of farmers' market use in the WIC Farmers' Market Nutrition Program (WIC FMNP), where participants who had previously used the farmers'

J Nutr Educ Behav. Author manuscript; available in PMC 2015 January 01. 
market as part of the program had higher farmers' market use rates. ${ }^{43}$ Thus, interventions should familiarize women who have limited experience shopping at farmers' markets to encourage more women to shop at them. For low income shoppers, conducting "get to know the farmers' market" programs at WIC and SNAP sites may help better familiarize such potential patrons with this new shopping environment. Incentivizing farmers' market shopping through vouchers and coupons, accepting SNAP Electronic Benefit Transfer (EBT) and WIC Farmers Market Nutrition Program coupons, and increasing awareness of the location of the farmers' market and the potential price savings may also entice first time shoppers. ${ }^{19,21}$

Interestingly, the majority of the women who were most willing to go to the farmers' market, or "positive deviants", did not currently shop at the farmers' market. They cited reasons like lack of familiarity and already having access to a garden. The women who were least willing to shop at the farmers' market, "negative deviants", cited factors related to convenience and safety as reasons for not shopping at the farmers' market. Developing a better understanding of these consumers should be an aim for future research, as interventions could be effectively designed around the uncommon behaviors displayed by these women who were most and least willing to shop at the market. ${ }^{32}$

An important strength of this research is that it provides some clarity to what percentage of price savings is required and how accessible the farmers' market must be in order to increase farmers' market use among low-income consumers. Consumers were presented with multiple representations (price versus amount) in order to assess the influence of price differentials, providing greater understanding of how different representations may influence willingness to shop. Lastly, learning more about what motivates low-income women to shop at farmers' markets will help inform how farmers' markets may stay economically viable in rural and low-income neighborhoods. Dissemination of these research findings may help others design successful programs to encourage use of farmers' markets among low-income consumers.

The limitations of this study include the small, purposeful sample, and lack of ability to generalize findings beyond low-income women. In addition, the produce presented in the scenarios was not individualized to the consumers' individual produce preferences, which may have influenced their responses. However, in the interviews, it was emphasized that the participant imagine their favorite produce as the produce purchased at the market, as opposed to what was pictured. The produce pictured represented current seasonal availability at the local farmers' market and supermarkets. Also, our results may be subject to social desirability bias, as the participants self-reported potential shopping behaviors versus investigators objectively tracking actual shopping behavior. Future studies should validate such self-reported behavior with behavior from actual market transactions. Two scenarios which may further clarify consumer behavior were not asked of participants: 1) identical price at the farmers' market compared to the supermarket, and 2) identical distance from the participants residence to the farmers' market or supermarket. Future research should investigate these scenarios. Finally, the revision to the qualitative interview guide is a limitation. However, iterative review of results and amending the methods is a frequently used qualitative strategy. ${ }^{44}$ 


\section{CONCLUSIONS AND IMPLICATIONS}

Participants in the present study shared "getting more for my money" and "quality for price" as important factors in the decision to shop at a farmers' market, even if that meant a longer drive to the farmers' market. Further, participants were more aware of the quantity or amount of produce purchased rather than the price of the produce purchased.

Consumer willingness to shop at farmers' markets is influenced by multiple factors, including product pricing, representation of pricing, and accessibility. Understanding consumer preferences is important to the success of any intervention to increase population fruit and vegetable consumption. Understanding consumer preferences is also important to inform economic vitality of farmers' markets. Future farmers' market planning efforts should take into account such consumer-level preferences.

\section{Acknowledgements}

Research reported in this publication was supported by Cooperative Agreement Number 5U48DP001944 from the Centers for Disease Control and Prevention (CDC) and by the National Institutes of Health/ National Cancer Institute under award number 5R03CA155362-02. Its contents are solely the responsibility of the authors and do not necessarily represent the views of the CDC or NIH.

\section{REFERENCES}

1. Van Duyn MA, Pivonka E. Overview of the health benefits of fruit and vegetable consumption for the dietetics professional: selected literature. J Am Diet Assoc. 2000; 100(12):1511-1521. [PubMed: 11138444]

2. Centers for Disease Control and Prevention. Centers for Disease Control and Prevention; Sept.. 2010 State-Specific Trends in Fruit and Vegetable Consumption Among Adults --- United States, 2000--2009. http://www.cdc.gov/mmwr/preview/mmwrhtml/mm5935a1.htm Web

3. Guenther P, Dodd K, Reedy J, Krebs-Smith S. Most Americans Eat Much Less than Recommended Amounts of Fruits and Vegetables. J Am Diet Assoc. 2006; 106(9):1371-1379. [PubMed: 16963342]

4. Cassady D, Jetter KM, Culp J. Is price a barrier to eating more fruits and vegetables for low-income families? J Am Diet Assoc. 2007; 107(11):1909-1915. [PubMed: 17964310]

5. Jilcott SB, Hurwitz J, Moore JB, Blake C. Qualitative perspectives on the use of traditional and nontraditional food venues among middle- and low-income women in Eastern North Carolina. Ecol Food Nutr. 2010; 49(5):373-389. [PubMed: 21888577]

6. Jilcott SB, Laraia BA, Evenson KR, Ammerman AS. Perceptions of the community food environment and related influences on food choice among midlife women residing in rural and urban areas: a qualitative analysis. Women Health. 2009; 49(2-3):164-180. [PubMed: 19533508]

7. Yeh MC, Ickes SB, Lowenstein LM, Shuval K, Ammerman AS, Farris R, et al. Understanding barriers and facilitators of fruit and vegetable consumption among a diverse multi-ethnic population in the USA. Health Promot Int. 2008; 23(1):42-51. [PubMed: 18182418]

8. Morland K, Diez Roux AV, Wing S. Supermarkets, other food stores, and obesity: the atherosclerosis risk in communities study. Am J Prev Med. 2006; 30(4):333-339. [PubMed: 16530621]

9. Jilcott SB, Wade S, McGuirt JT, Wu Q, Lazorick S, Moore JB. The association between the food environment and weight status among eastern North Carolina youth. Public Health Nutr. 2011:1-8. [PubMed: 21211099]

10. Rose D, Richards R. Food store access and household fruit and vegetable use among participants in the US Food Stamp Program. Public Health Nutr. 2004; 7(8):1081-8. [PubMed: 15548347] 
11. Larson N, Story M. A review of environmental influences on food choices. Ann Behav Med. 2009; 38(Suppl 1):S56-73. [PubMed: 19802648]

12. Larson NI, Story MT, Nelson MC. Neighborhood environments: disparities in access to healthy foods in the U.S. Am J Prev Med. 2009; 36(1):74-81. [PubMed: 18977112]

13. Bodor JN, Rose D, Farley TA, Swalm C, Scott SK. Neighbourhood fruit and vegetable availability and consumption: the role of small food stores in an urban environment. Public Health Nutr. 2008; 11(4):413-420. [PubMed: 17617930]

14. Wrigley N, Warm D, Margetts B, Whelan A. Assessing the Impact of Improved Retail Access on Diet in a 'Food Desert': A Preliminary Report. Urban Studies. 2002; 39(11):2061-2082.

15. Fisher, A. Hot Peppers and Parking Lot Peaches: Evaluating Farmers Markets in Low-Income Communities. Community Food Coalition; Venice, CA: 1999. http://www.foodsecurity.org/ HotPeppersPeaches.pdf

16. McCormack LA, Laska MN, Larson NI, Story M. Review of the nutritional implications of farmers' markets and community gardens: a call for evaluation and research efforts. J Am Diet Assoc. 2010; 110(3):399-408. [PubMed: 20184990]

17. Sommer R, Wing M, Aitkens S. Price savings to consumers at farmers markets. J Consum Aff. 1980; 14:452-463.

18. McGuirt JT, Jilcott SB, Liu H, Ammerman AS. Produce Price Savings for Consumers at Farmers' Markets Compared to Supermarkets in North Carolina. J Hunger Environ Nutr. 2011; 6(1):86-98.

19. Herman DR, Harrison GG, Afifi AA, Jenks E. Effect of a targeted subsidy on intake of fruits and vegetables among low-income women in the Special Supplemental Nutrition Program for Women, Infants, and Children. Am J Public Health. 2008; 98(1):98-105. [PubMed: 18048803]

20. Cromp D, Cheadle A, Solomon L, Maring P, Wong E, Reed K. Kaiser Permanente's Farmers' Market Program. Description, impact, and lessons learned. Journal of Agriculture, Food Systems and Community Development. 2012; 2(2):29-36.

21. Anderson JV, Bybee DI, Brown RM, McLean RF, Garcia EM, Breer ML, Schillo BA. 5 A day fruit and vegetable intervention improves consumption in a low income population. J Am Diet Assoc. 2001; 101:195-202. [PubMed: 11271692]

22. Evans A, Jennings R, Smiley A, Medina J, Sharma S, Rutledige R, Stigler M, Hoelscher D. Introduction of farm stands in low-income communities increases fruit and vegetable among community residents. Health Place. 2012; 18(5):1137-1143. [PubMed: 22608130]

23. Grace C, Grace T, Becker N, Lyden J. Barriers to Using Urban Farmers' Markets: An Investigation of Food Stamp Clients' Perceptions. J Hunger Environ Nutr. 2008; 2(1):55-75.

24. Byker C, Shanks J, Misyakc S, Serranoc E. Characterizing Farmers' Market Shoppers: A Literature Review. J Hunger Environ Nutr. 2012; 7(1):38-52.

25. Baker D, Hamshaw K, Kolodinsky J. Who Shops at the Market? Using Consumer Surveys to Grow Farmers' Markets: Findings from a Regional Market in Northwestern Vermont. Journal of Extension. 2009; 47(6):1-9.

26. Yeh MC, Ickes SB, Lowenstein LM, Shuval K, Ammerman AS, Farris R, Katz DL. Understanding barriers and facilitators of fruit and vegetable consumption among a diverse multi-ethnic population in the USA. Health Promot Int. 2008; 23(1):42-51. [PubMed: 18182418]

27. Carson R, Hanemann WM. Mäler KG, Vincent JR. Contingent Valuation. Handbook of Environmental Economics. 2006:821-936.

28. Glanz K, Basil M, Maibach E, Goldberg J, Snyder D. Why Americans eat what they do: taste, nutrition, cost, convenience, and weight control concerns as influences on food consumption. $\mathrm{J}$ Am Diet Assoc. 1998; 98(10):1118-1126. [PubMed: 9787717]

29. Pitt County QuickFacts from the US Census Bureau. Web. 2012. http://quickfacts.census.gov/qfd/ states/37/37147.html>

30. Greenville (city) QuickFacts from the US Census Bureau. Web. 2012. <http:// quickfacts.census.gov/qfd/states/37/3728080.html>

31. Flaccavento, A. A Comparison of Farmers Markets and Supermarkets in Nineteen Communities in the Southeast. SCALE, Inc.; 2011.

32. Marsh DR, Schroeder DG, Dearden KA, Sternin J, Sternin M. The power of positive deviance. BMJ. 2004; 329(7475):1177-1179. [PubMed: 15539680] 
33. Glanz, K.; Rimer, BK.; Viswanath, K., editors. Health Behavior and Health Education: Theory, Research, and Practice. 4th. Jossey-Bass; 2008.

34. Ashman L, Vega J, Dehan M, Fisher A, Hippler R, Romain B. Seeds of Change: Strategies for Food Security for the Inner City. The Community Food Security Coalition. 1993

35. Lawson L, McNally M. Rethinking Direct Marketing Approaches Appropriate to Low and Moderate-income Commnities and Urban Market Gardens. IC SAREP. 1997

36. Hawkes C. Sales promotions and food consumption. Nutr Rev. 2009; 67(6):333-342. [PubMed: 19519674]

37. Schnotz, Wolfgang; Raymond W, Kulhavy. Comprehension of Graphics. North-Holland; Amsterdam: 1994. Print

38. Just, David R.; Lisa, Mancino; Brian, Wansink. USDA ERS - Could Behavioral Economics Help Improve Diet Quality for Nutrition Assistance Program Participants? USDA. Jun.2007 Web.

39. Alford B, Biswas A. The effects of discount level, price consciousness and sale proneness on consumers' price perception and behavioral intention. J Bus Res. 2002; 55:775-783.

40. Monroe, KB. Pricing: Making Profitable Decisions. 2nd. McGraw-Hill; New York: 1990.

41. Mei-Lien L. A mediating influence on customer loyalty: The role of perceived value. Journal of Management and Marketing Research. 2011:1-12.

42. Hirschman EC, Holbrook MB. Hedonic Consumption: Emerging Concepts, Methods and Propositions. Journal of Marketing. 1982; 46:92-101.

43. Racine EF, Smith Vaughn A, Laditka SB. Farmers' market use among African-American women participating in the Special Supplemental Nutrition Program for Women, Infants, and Children. J Am Diet Assoc. 2010; 110(3):441-446. [PubMed: 20184995]

44. Ulin, Priscilla R.; Elizabeth, T. Robinson; Elizabeth, E. Tolley Qualitative Methods in Public Health: A Field Guide for Applied Research. Jossey-Bass; San Francisco: 2005. Print

J Nutr Educ Behav. Author manuscript; available in PMC 2015 January 01. 
Would you be willing to shop at the farmers' market in each of the following scenarios $($ Yes/No)?

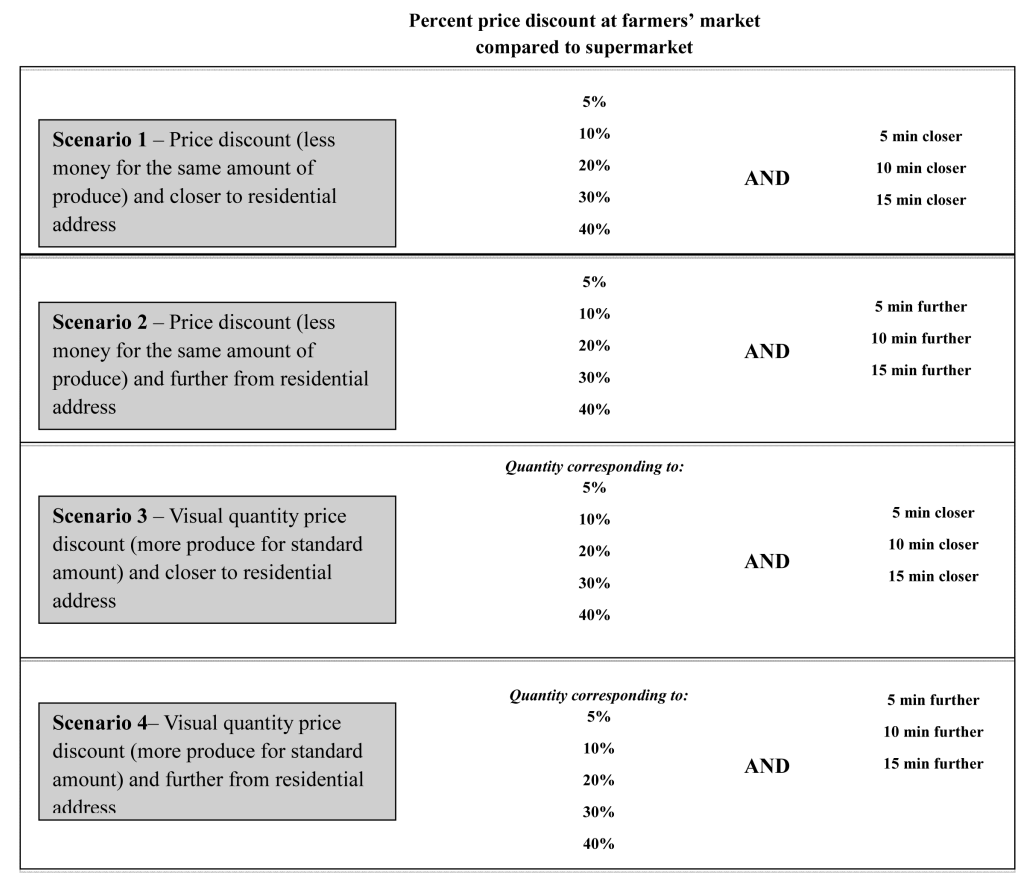

Figure 1.

Diagram of Contingent Valuation Exercise Price and Accessibility Scenarios 


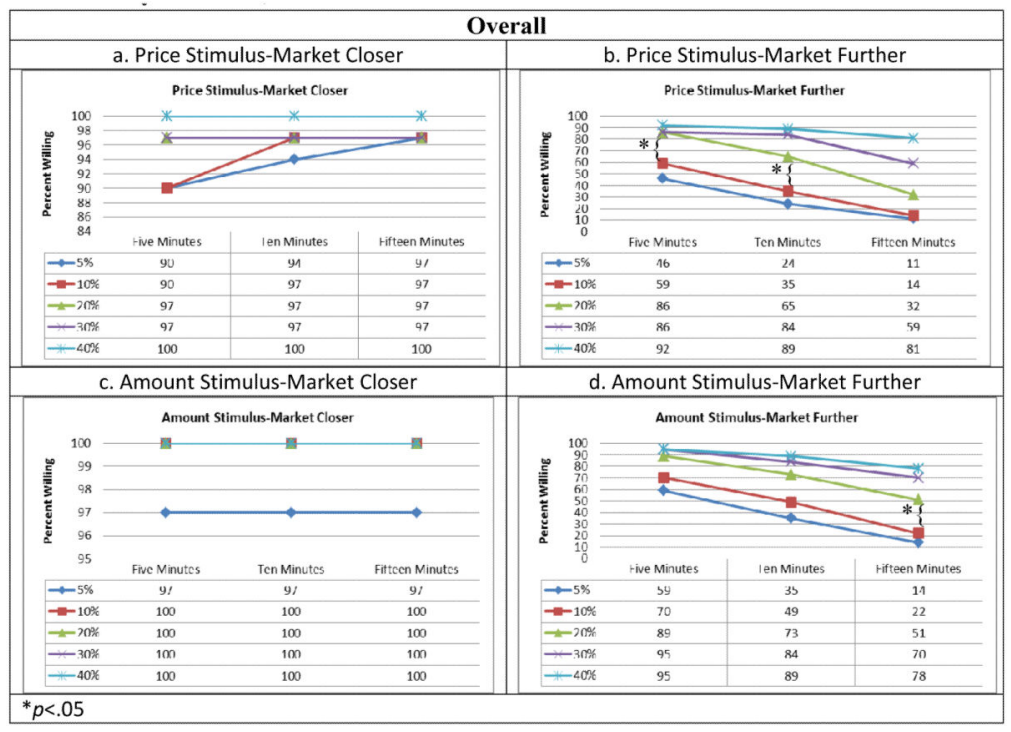

Figure 2.

Percentage of Consumers Willing to Shop at Farmers' Market for Price and Accessibility Scenarios, Overall 